\title{
Workshop untuk Pembuatan Bahan Ajar Ilmu Pengetahuan Alam Berbasis Kearifan Lokal Sidoarjo
}

\author{
Noly Shofiyah $^{1}$, Fitria Nur Hasanah ${ }^{2}$, Siti Miluningtias ${ }^{3}$ \\ Universitas Muhammadiyah Sidoarjo ${ }^{1,2,3}$ \\ nolyshofiyah@umsida.ac.id*, fitrianh@umsida.ac.id, sitimiluningtyas@gmail.com
}

\begin{abstract}
The main problem that occurred in SMP Negeri 2 Jabon, which inspired this activity was the pedagogical competence of science teachers on aspects of making teaching materials and the implementation of science learning in the classroom that had not yet integrated local wisdom into science learning. In other words when making teaching materials teachers rarely associate the concept of science with local culture in Sidoarjo. Therefore, in order for teachers to be able to make teaching materials based on local wisdom or ethnoscience, a workshop was held with the aim of: 1) Improving teacher's concepts understanding of ethnoscience, local wisdom or local culture, 2) Enhancing teacher skills in making teaching materials based on local wisdom. In delivering innovations to partners, it is carried out by the method of explanation, discussion, practice and mentoring and evaluation stages. The result of this activity is the knowledge of teachers about learning science based on local wisdom or ethnoscience increased. This is indicated by an average pre-test 58.3 and post-test 76.7. In addition, the teachers are able to make science teaching materials based on local wisdom or ethnoscience. Some of the teaching materials that have been made by the teachers are learning materials integrated with traditional games; Science worksheets with the theme of smoking fish; and worksheets for making "klompen".
\end{abstract}

Keywords: Science Learning; Local Wisdom; Ethnoscience.

\begin{abstract}
Abstrak
Permasalah pokok yang terjadi di SMP Negeri 2 Jabon, yang menginspirasi dari kegiatan ini adalah kompetensi pedagogik guru IPA pada aspek pembuatan perangkat pembelajaran dan implementasi pembelajaran IPA di kelas yang belum mengintegrasikan budaya lokal ke dalam pembelajaran IPA. Dalam kata lain ketika membuat perangkat pembelajaran guru jarang mengkaitkan konsep IPA dengan kebudayaan lokal di Sidoarjo. Oleh karena itu, supaya guru-guru mampu membuat bahan ajar IPA berbasis kearifan lokal atau etnosains, maka diadakan workshop dengan tujuan 1) Meningkatkan pemahaman guru tentang konsep etnosains, kearifan local atau budaya local, 2) Meningkatkan keterampilan guru dalam pembuatan bahan ajar berabasis kearifan local. Dalam penyampaian inovasi kepada mitra, dilakukan dengan metode penjelasan, diskusi, praktek serta dilakukan tahapan pendampingan dan evaluasi. Hasil dari kegiatan ini adalah pengetahuan guruguru tentang pembelajaran IPA berbasis kearifan lokal atau etnosains meningkat. Hal ini ditunjukkan dengan nilai rata-rata pre-test 58,3 dan post-test 76,7. Selain itu, guru-guru IPA juga mampu membuat bahan ajar IPA berbasis kearifan lokal atau etnosains. Beberapa bahan ajar yang
\end{abstract}


berhasil dibuat adalah bahan ajar IPA terintegrasi permainan tradisional engklek dan balap klompen; LKS IPA dengan tema pengasapan ikan; serta LKS pembuatan klompen.

Kata Kunci: Pembelajaran IPA; Kearifan Lokal; Etnosains.

\section{A. PENDAHULUAN}

Kota Sidoarjo atau yang biasa disebut dengan sebutan Kota Udang ini yaitu salah satu kabupaten yang ada di provinsi Jawa Timur. Kota Petis ini juga memiliki banyak kebudayan, makanan khas, dan ciri khas. Jabon merupakan salah satu kecamatan di kabupaten Sidoarjo.

Secara Etnografi, Kecamatan Jabon merupakan kawasan pertambakan sehingga bentuk potensi lokal kawasannya adalah ikan tawar, segala macam rerumputan laut, berbagai macam jenis mangrove, dll. Lebih tepatnya, keunggulan lokal di Kecamatan Jabon ini adalah segala sesuatu yang berkaiatan dengan pengolahan hasil tambak, seperti pembuatan ikan menjadi kerupuk, pengasapan ikan (Ikan Asap), Petis Udang, serta Mangrove, (Wachidah \& Wardana, 2018).

SMP Negeri 2 Jabon merupakan Sekolah yang terletak di Desa Permisan, Kec. Jabon, Kabupaten Sidoarjo. Guru-guru IPA yang mengajar di SMPN 2 Jabon sebagian besar adalah PNS, Mereka mempunyai latar belakang pendidikan Fisika dan Kimia. Karena pada dahulu kala belum ada program studi pendidikan IPA. Berdasarkan hasil observasi yang dilakukan oleh mahasiswa IPA yang melakukan magang di SMP Negeri 2 Jabon, menjelaskan bahwa guru-guru IPA jarang melakukan inovasi pembelajaran melalui sebuah penelitian. Model-model pembelajaran yang diterapkan dalam pembelajaran sudah sesuai dengan kurikulum 2013, namun belum dikembangkan sesuai dengan kearifan lokal Sidoarjo. Hal ini dapat diketahui dari RPP yang dibuat dan LKS/LKPD yang digunakan oleh guru-guru IPA SMPN 2 Jabon yang cenderung monoton dari tahun ke tahun. Sebagai contoh Lembar Kerja Siswa (LKS) yang digunakan hanya bersumber dari buku paket (BSE) yang mana kegiatan praktikumnya kurang mengkaitkan dengan kontekstual atau peristiwa-peristiwa yang dikenal oleh siswa-siswa SMP Negeri 2 Jabon. Hal ini tentunya berdampak pada aktivitas pembelajaran di kelas yang kurang bermakna bagi siswa khusunya di lingkungan pertambakan, sehingga minat belajar siswa rendah. Rendahnya minat belajar siswa nanti tentunya akan berdampak pula pada hasil belajar siswa yang rendah.

Pembelajaran IPA berbasis budaya lokal atau kearifan lokal merupakan salah satu pendekatan pembelajaran yang perlu terus dikembangkan. Pembelajaran IPA yang diintegrasikan dengan budaya Lokal akan menjadikan pembelajaran tersebut lebih bermakna bagi siswa. Budaya-budaya yang ada di masing-masing daerah dapat diintegrasikan dalam pembelajaran IPA. Salah satu contohnya adalah pembuatan Ikan Mujair Asap di Desa Permisan, Jabon. Proses pembuatannya adalah Ikan Mujair segar dibersihkan dan dicuci dengan air yang mengalir. Setelah itu, ikan ditusuk seperti sate dengan tusuk ikan berbahan besi. Tiap tusuknya terdiri dari 10 ikan. Kemudian, ikan yang sudah ditusuk tersebut dipanggang di atas tungku pembakaran dengan menggunakan bahan bakar tempurung kelapa. Tempurung kelapa digunakan sampai pada saat ini dikarenakan menghasilkan bara yang stabil. Dalam hal ini, asap lebih 
dibutuhkan dalam pembuatan ikan asap ketimbang api. Dibutuhkan waktu sekitar 3 jam sampai ikan mujair terlihat berwarna kecoklatan. Dari proses pembuatan ikan asap dapat diekplorasi konsep-konsep IPA, yaitu: Energi Potensial, Kalor, Perpindahan Kalor Konduksi dan Konveksi, (Perwitasari, Sudarmin, \& Linuwih, 2016). Budaya Lokal ini dapat diintegrasikan dalam pembelajaran IPA. Pembelajaran IPA berbasis budaya lokal dimana di dalam pembelajaran tersebut terdapat praktikum, telah banyak dilakukan dan terbukti efektif dalam meningkatkan minat atau motivasi siswa (Shidiq, 2016), hasil belajar siswa (Damayanti, Rusilowati, \& Linuwih, 2017), keterampilan berpikir kritis siswa/mahasiswa (Arfianawati, Sudarmin, \& Sumarni, 2016); (Temuningsih, Peniati, \& Marianti, 2017), kompetensi dasar sains dan nilai kearifan lokal (Suastra, 2010).

Berdasarkan dari banyaknya penelitian dan artikel ilmiah terkait pembelajaran berbasis budaya Lokal yang hasilnya menunjukkan efektif dalam meningkatkan hasil belajar siswa, namum guru-guru IPA di SMP Negeri 2 Jabon belum banyak yang memahaminya. (Suardana \& Retug, 2017) menjelaskan bahwa guru-guru sains SMP belum memahami sains asli (budaya lokal) yang dapat diintegrasikan ke dalam pembelajaran, walaupun sesungguhnya tanpa disadari mereka telah menyinggungnya dalam pembelajaran IPA yang sedang diajarkannya. Misalnya, penggunaan garam dapur untuk pengawetan ikan. Di samping itu, guru-guru IPA SMP Negeri 2 Jabon juga masih mengalami kesulitan dalam mengimplementasikan pembelajaran IPA berbasis kearifan lokal dan mengganggap pembelajaran IPA berbasis kearifan lokal sulit dilaksanakan. Mereka juga menyatakan bahwa untuk praktikum IPA di luar laboratorium atau bersifat outdoor sangat jarang bisa dilakukan karena keterbatasan waktu yang tersedia. Oleh karena itu untuk membantu guru dalam meningkatkan kemampuannya dalam melakukan pembelajaran IPA berbasis budaya lokal, akan dilakukan pelatihan dan pendambingan bagi guru di SMP negeri 2 Jabon.

\section{B. PELAKSAAAN DAN METODE}

Kegiatan workshop ini menggunakan metode aplikais strategi pembelajaran dimana diawali dengan mengidentifikasi permasalahan-permasalahan yang ada di kalangan guru. Selanjutnya, pengabdi melakukan diskusi dengan sekolah mitra untuk menentukan akar permasalahan utama pembelajaran IPA di kelas dan sekaligus merumusakan solusi penyelesaian masalah yang sesuai. Permasalahan dan solusi yang ditawarkan dijelaskan pada tabel 1.

Tabel 1. Keterkaitan antara Masalah Mitra dengan Solusi Pemecahan

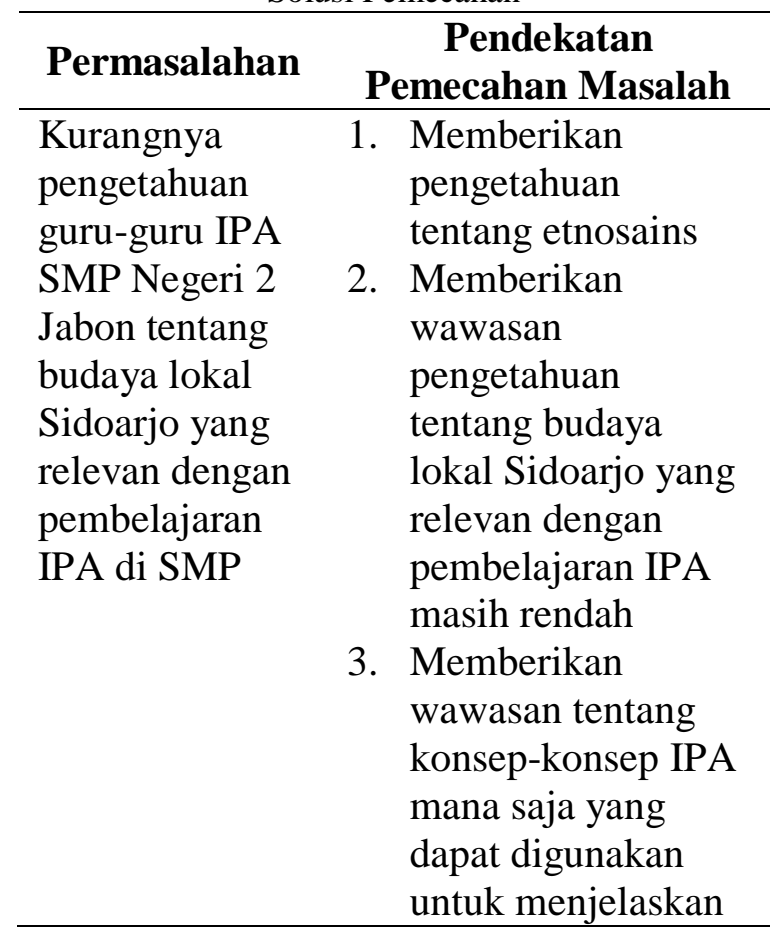




\begin{tabular}{|c|c|}
\hline Per & $\begin{array}{c}\text { Pendekatan } \\
\text { Pemecahan Masalah }\end{array}$ \\
\hline & $\begin{array}{l}\text { suatu budaya } \\
\text { Sidoarjo. }\end{array}$ \\
\hline $\begin{array}{l}\text { Kurangnya } \\
\text { pemahaman } \\
\text { guru-guru IPA } \\
\text { SMP Negeri } 2 \\
\text { Jabon tentang } \\
\text { cara } \\
\text { mengintegrasik } \\
\text { an budaya lokal } \\
\text { Sidoarjo ke } \\
\text { dalam } \\
\text { pembelajaran } \\
\text { IPA di kelas }\end{array}$ & 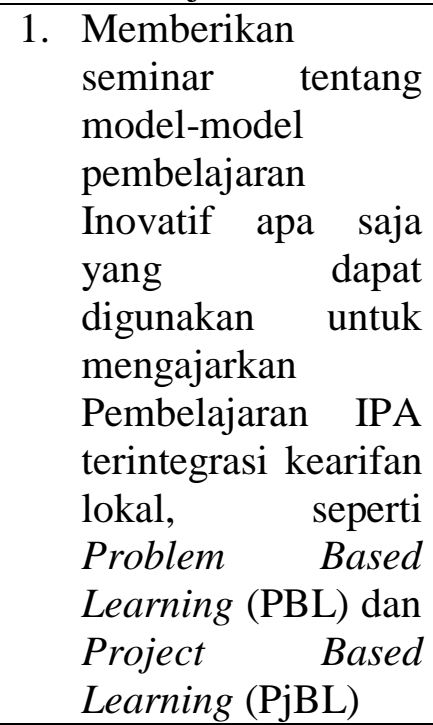 \\
\hline $\begin{array}{l}\text { Kurangnya } \\
\text { kemampuan } \\
\text { guru-guru IPA } \\
\text { SMP Negeri 2 } \\
\text { Jabon dalam } \\
\text { membuat } \\
\text { perangkat } \\
\text { pembelajaran } \\
\text { mulai dari RPP, } \\
\text { Bahan Ajar, } \\
\text { LKS dan } \\
\text { Penilaian } \\
\text { berbasis } \\
\text { kearifan lokal } \\
\text { Sidoarjo. }\end{array}$ & 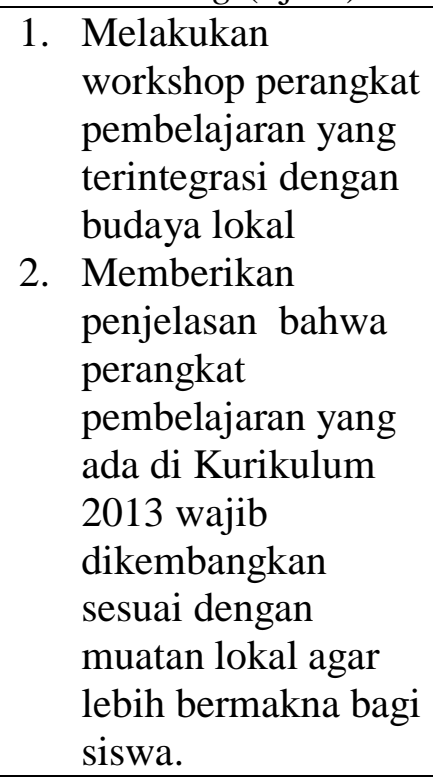 \\
\hline $\begin{array}{l}\text { Guru belum } \\
\text { menerapkan } \\
\text { pembelajaran } \\
\text { IPA berbasis } \\
\text { kearifan lokal di } \\
\text { kelas }\end{array}$ & $\begin{array}{l}\text { 1. Melakukan } \\
\text { pendampingan bagi } \\
\text { guru-guru IPA } \\
\text { ketika } \\
\text { mengimplementasik } \\
\text { an pembelajaran } \\
\text { IPA terintegrasi } \\
\text { kearifan lokal } \\
\text { dengan }\end{array}$ \\
\hline
\end{tabular}

Adapun tahapan kegiatan dalam workshop pembuatan bahan ajar IPA berbasis kaerifan lokal adalah: (1) pre-test pemahaman guru tentang kearifan lokal dan etnosains, (2) pemaparan materi tentang etnosains dan kearifan lokal, serta modelmodel pembelajaran inovatif yang sesuai untuk mengajarkan IPA berbasis kearifan lokal, (3) Pendampingan pembuatan bahan ajar berbasis kearifan lokal, dan (4) post-test pemahaman guru tentang kearifan lokal dan etnosains.

\section{HASIL DAN PEMBAHASAN}

Kegiatan pengabdian ini telah dilaksanakan pada hari Rabu dan Kamis, 1819 Maret 2020 di SMP Negeri 2 Jabon. Keberhasilan dari kegiatan ini dapat dilihat dari indikator: 1) meningkatnya pengetahuan dan pemahaman guru tentang etnosains dan kearifan lokal, 2) guru mampu membuat bahan ajar IPA berbasis kearifan lokal Sidoarjo.

1. Peningkatan pemahaman guru tentang etnosains dan kearifan lokal

Sebelum dilakukan pelatihan atau workshop tentang pembelajaran IPA berbasis etnosains atau kearifan lokal, guru-guru diminta untuk mengerjakan pre-test. Terdapat 10 pernyataan dalam pre-test dan post-test, dan guru diminta memilih apakah penyataan tersebut "benar" atau "salah". Hal ini dilakukan untuk mengetahui sejauh mana pemahaman guru tentang perbedaan istilahistilah yaitu etnosains, kearifan lokal, 
indigenous knowledge dan pembelajaran IPA berbasis etnosains dan kearifan lokal.

Tabel 2. Nilai Pre-test dan Post-test

\begin{tabular}{lcc}
\hline Guru & Pretest & Posttest \\
\hline Guru 1 & 70 & 70 \\
Guru 2 & 50 & 80 \\
Guru 3 & 50 & 80 \\
Guru 4 & 60 & 80 \\
Guru 5 & 70 & 80 \\
Guru 6 & 50 & 70 \\
Rata-rata & 58,3 & 76,7 \\
\hline
\end{tabular}

Tabel 1 menunjukan bahwa hasil pretest dan post-test dimana terdapat peningkatan pemahaman guru tentang pembelajaran IPA berbasis kearifan lokal. Selain itu, guru-guru di SMP Negeri 2 Jabon juga berpartisipasi aktif pada saat pelatihan. Hal ini ditunjukkan dengan respon guru terhadap pemateri dalam bentuk bertanya, menanggapi dan menceritakan pengalaman mengajarnya pada saat pembelajaran IPA materi bioteknologi konvensional membuat tape. Hal ini membuktikan bahwa guru tertarik dengan materi yang diberikan oleh pemateri. Selain itu, mereka menyatakan bahwa mereka belum banyak mengetahui budaya Sidoarjo yang relevan dengan materi IPA yang dapat diintegrasikan dalam pembelajaran di kelas dikarenakan mereka bukan asli penduduk Sidorajo. Mereka adalah guru-guru PNS yang berasal dari luar kota Sidoarjo. Oleh karena itu, workshop ini sangat bermanfaat bagi guru-guru IPA terutama dalam membantu mereka menyusun bahan ajar berbasis kearifan lokal atau etnosains. Modul pembelajaran yang berorientasi pada etnosains dapat meningkatkan hasil belajar peserta didik (Lia, Udaibah, \& Mulyatun, 2016) dan model pembelajaran yang menggunakan pendekatan etnosains juga mampu mengembangkan keterampilan generic sains siswa,(Rosidah, Hidayah, \& Astuti, 2018).

2. Guru mampu membuat bahan ajar IPA berorientasi etnosains atau kearifan lokal Sidoaro

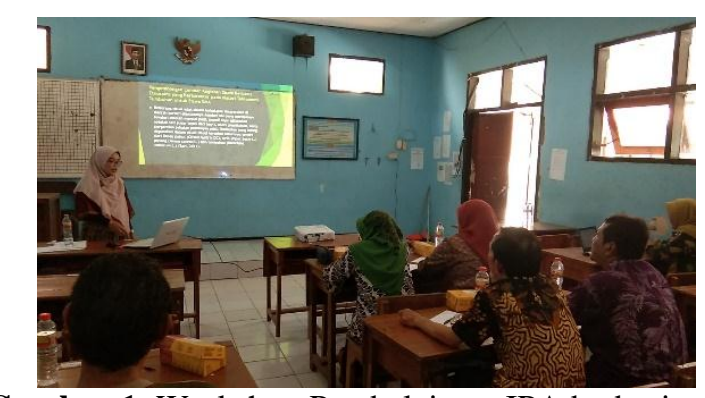

Gambar 1. Workshop Pembelajaran IPA berbasis Kearifan Lokal

Penyampain materi tentang konsep dasar etnosains dan kearifan lokal, serta model-model pembelajaran inovatif yang sesuai untuk mengajarkan IPA berbasis kearifan lokal (Gambar 1) mampu meningkatkan wawasan guru-guru tentang budaya-budaya Sidoarjo yang dapat diintegrasikan dalam pembelajaran IPA. Selain dapat dinilai dari nilai post-test nya yang meningkat, hal ini juga terlihat dari keterampilan guru dalam membuat bahan ajar IPA SMP berbasis kearifan lokal Sidoarjo. Pada saat pelatihan dibagi menjadi 3 kelompok dimana setiap kelompok terdiri dari 2 Guru. 2 kelompok merupakan guru IPA dan 1 kelompok guru Prakarya. Guruguru bersepakat untuk membuat bahan ajar pada materi semester ganjil. Hal tersebut dilakukan karena pelatihan berlangsung pada saat siswa-siswa diminta untuk belajar di rumah karena pandemic Covid-19, Sehingga tidak dimungkinkan untuk mengimplementasikan bahan ajar yang sudah dibuat pada semester genap.

Berikut adalah hasil dari pendampingan pembuatan bahan ajar IPA berbasis kearifan lokal Sidoarjo: 
Kelompok 1 memilih KD 3.2 Menganalisis gerak lurus, pengaruh gaya terhadap gerak berdasarkan hukum Newton, dan penerapannya pada gerak benda dan gerak makhluk hidup dengan mengintegrasikan pada permainan tradisonal Sidoarjo yaitu permainan engklek dan balap klompen.

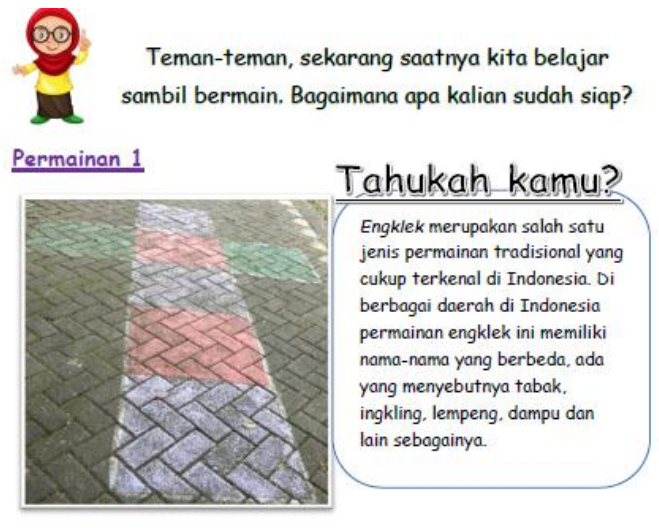

Gambar 1: Permainan Engklek

Gambar 2. Bahan Ajar IPA berbasis Permainan Tradisional Sidoarjo

Bahan ajar yang dibuat oleh kelompok 1 mengangkat tema permainan tradisonal yaitu permianan engklek dan permainan balap klompen. Melalui permainan engklek, siswa diharapkan dapat memahami perbedaan definisi antara jarak dan perpindahan, serta kelajuan dan kecepatan rata-rata dengan bermain dan belajar. Pada implementasi pembelajarannya, siswa diminta untuk melakukan permainan engklek dengan berpindah dari satu kotak ke kotak yang lainnya, kemudian siswa diminta untuk menghitung berapa jarak dan perpindahan yang ditempuh. Bersamaan dengan siswa bermain, siswa lainnya diminta untuk mengukur waktu tempuhnya. Selanjutnya dari jarak dan perpindahan yang diperoleh, mereka dapat menentukan kelajuan dan kecepatan rata-ratanya. Melalui desain pembelajaran IPA berbasis permaianan tradisional, siswa tidak akan merasa bosan dan tentunya akan lebih mudah dalam memahami konsep IPA yang diajarkan.
Kelompok 2 memilih KD 3.5 Memahami konsep energi, berbagai sumber energi, dan perubahan bentuk energi dalam kehidupan sehari-hari dengan mengintegrasikan pada "Pengasapan Ikan Nila/Mujaer"

LKPD Tema Pembuatan Ikan Asap Nila

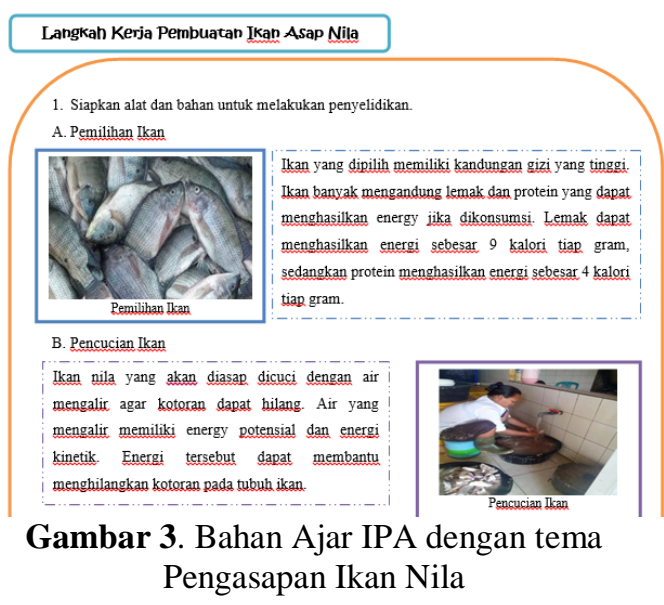

Pada LKPD yang dibuat oleh kelompok 2 dengan mengusung tema "Pembuatan Ikan Asap Nila", siswa diminta untuk melakukan penyelidikan dengan langkah langkah sebagai berikut: (1) Pemilihan ikan, ikan nila yang dipilih adalah yang berkualitas bagus; (2) Pencucian Ikan, ikan nila harus dicuci dengan air yang mengalir agar kotoran dapat hilang; (3) Pelapisan perut ikan dengan kertas, kertas merupakan bahan isolator sehingga energi panas tidak langsung mengenai tubuh ikan; (4) Penusukan ikan dengan btang besi dan dipanggang di atas tungku pembakar. Hal tersebut dilakukan agar panas merata ke seluruh bagian dalam ikan sehingga cepat matang.

Melalui pembelajaran tersebut, siswa dapat membangun konsep sains tentang kalor serta energi dan perubahannya dari kearifan lokal yang ada di daerah siswa tersebut yaitu pembuatan ikan asap nila.

Kelompok 3, yang merupakan guru prakarya membuat lembar kerja siswa tentang pembuatan klompen. 
Klompen atau dalam bahasa Indonesia bakiak merupakan sejenis sandal yang terbuat dari kayu. Klompen ini biasanya dimodifikasi untuk digunakan dalam perlombaan memperingati hari kemerdekaan Indonesia. Dalam pembuatan kelompen ini, siswa diminta untuk membuat kelompen sekreatif mungkin dan nantinya dapat digunakan dalam permaianan. Melalui permainan perlombaan kelompen, siswa diharapkan dapat juga memahami konsep jarak dan perpindahan serta kelajuan dan kecepatan rata-rata.

\section{PENUTUP}

\section{Simpulan}

Berdasarkan uraian-uraian sebelumnya, maka dapat disimpulkan:

Pengetahuan guru-guru tentang pembelajaran IPA berbasis kearifan lokal atau etnosains meningkat. Hal ini ditunjukkan dengan nilai rata-rata pre-test 58,3 dan post-test 76,7 .

Guru-guru mampu membuat bahan ajar IPA berbasis kearifan lokal atau etnosains, yaitu bahan ajar "gerak dan gaya" yang diintegrasikan dengan permainan tradisional dan bahan ajar "Energi dan Perubahannya" yang diintegrasikan dengan karifan lokal pengasapan ikan.

\section{Saran}

Guru-guru IPA dan Prakarya di SMP Negeri 2 Jabon Sidoarjo dapat mengembangkan secara mandiri Bahan Ajar atau Lembar Kerja Peserta Didik (LKPD) dengan mengintegrasikan kearifan lokal/budaya lokal Sidoarjo pada tema atau topic yang lain selain gerak dan gaya serta Energi dan Perubahannya

\section{Ucapan Terima Kasih}

Penulis mengucapkan terima kasih kepada Direktorat Riset dan Pengabdian Masyarakat Universitas Muhammadiyah Sidoarjo yang telah memberikan dukungan secara financial melalui program Hibah Institusi. Selain itu, penulis juga ingin mengapresiasi guru-guru IPA di SMP Negeri 2 Jabon yang telah berpartisipasi aktif dalam kegiatan ini.

\section{E. DAFTAR PUSTAKA}

Arfianawati, S., Sudarmin, S., \& Sumarni, W. (2016). Model pembelajaran kimia berbasis etnosains untuk meningkatkan kemampuan berpikir kritis siswa. Jurnal Pengajaran MIPA, 21(1), 4651.

Damayanti, C., Rusilowati, A., \& Linuwih, S. (2017). Pengembangan model pembelajaran ipa terintegrasi etnosains untuk meningkatkan hasil belajar dan kemampuan berpikir kreatif. Journal of Innovative Science Education, 6(1), 116-128.

Lia, R. M., Udaibah, W., \& Mulyatun, M. (2016). Pengembangan Modul Pembelajaran Kimia Berorientasi Etnosains Dengan Mengangkat Budaya Batik Pekalongan. Unnes Science Education Journal, 5(3), 1418-1423.

Perwitasari, T., Sudarmin, S., \& Linuwih, S. (2016). Peningkatan literasi sains melalui pembelajaran energi dan perubahannnya bermuatan etnosains pada pengasapan ikan. Jurnal

Penelitian Pendidikan IPA, 1(2), 6270.

Rosidah, T., Hidayah, F. F., \& Astuti, A. P. (2018). Efektivitas Model

Pembelajaran Problem Based Instruction Berpendekatan Etnosains Untuk Meningkatkan Prestasi Belajar 
Siswa Pada Materi Stoikiometri. In

Prosiding Seminar Nasional \&

InternasionaL (pp. 385-394).

Shidiq, A. S. (2016). Pembelajaran sains

kimia berbasis etnosains untuk

meningkatkan minat dan prestasi

belajar siswa. In In Seminar Nasional

Kimia dan Pendidikan Kimia (SNKPK)

VIII (pp. 27-236).

Suardana, I. N., \& Retug, N. (2017).

Pelatihan pembuatan perangkat

pembelajaran berbasis budaya Bali bagi

guru-guru sains SMP di Kecamatan

Buleleng. WIDYA LAKSANA, 2(1), 9-

19.

Suastra, I. W. (2010). Model Pembelajaran

Sains Berbasis Budaya Lokal Untuk

Mengembangkan Potensi Dasar Sains

dan Nilai Kearifan Lokal di SMP.

Jurnal Pendidikan Dan Pengajaran, 43(1).

Temuningsih, T., Peniati, E., \& Marianti, A. (2017). Pengaruh Penerapan Model

Problem Based Learning

Berpendekatan Etnosains Pada Materi

Sistem Reproduksi terhadap

Kemampuan Berpikir Kritis Siswa.

Journal of Biology Education, 6(1), 70-79.

Wachidah, K., \& Wardana, M. D. K. (2018).

Desain pembelajaran sekolah dasar

berbasis kearifan lokal di kawasan

pertambakan kabupaten sidoarjo. JPD:

Jurnal Pendidikan Dasar, 9(1), 156-

165. 